From the Institut Jules Bordet; European Organization for Research and Treatment of Cancer, Brussels; Hasselt University, Diepenbeek; International Drug Development Institute, Louvain-laNeuve; University Hospital Gasthuisberg, Leuven, Belgium; Indiana University-Purdue University, Indianapolis, IN; Astra-zeneca, Macclesfield; Nottingham City Hospital, Nottingham, United Kingdom; Medizinische Hochschule, Hannover, Germany; University of Alberta, Edmonton, Alberta, Canada; Breast Cancer Research Institute-La

Prandie, Valojoulx; Centre Oscar Lambret, Lille, France; Hospital of Prato, Prato, Italy; Medical University of Gdańsk, Gdańsk, Poland; Erasmus MC University Medical Center, Rotterdam, the Netherlands; and Marmara University Hospital, Istanbul, Turkey.

Submitted January 18, 2007; accepted September 18, 2007.

Supported by the IAP research network $\mathrm{P} 6 / 03$ of the Belgian government (T.B.). No financial support was sought from any of the trial sponsors.

Authors' disclosures of potential conflicts of interest and author contributions are found at the end of this article.

Corresponding author: Martine $\mathrm{J}$

AQ: L Piccart-Gebhart, MD, Institut Jules Bordet, 121 boulevard de Waterloo, 1000 Brussels, Belgium; e-mail: martine.piccart@bordet.be.

(C) 2008 by American Society of Clinical Oncology

0732-183X/08/2612-1/\$20.00

DOI: 10.1200/JCO.2007.10.8399

\title{
Effects of Taxanes Alone or in Combination With Anthracyclines As First-Line Therapy of Patients With Metastatic Breast Cancer
}

Martine J. Piccart-Gebhart, Tomasz Burzykowski, Marc Buyse, George Sledge, James Carmichael, Hans-Joachim Luck, John R. Mackey, Jean-Marc Nabholtz, Robert Paridaens, Laura Biganzoli, Jacek Jassem, Marijke Bontenbal, Jacques Bonneterre, Stephen Chan, Gul Atalay Basaran, and Patrick Therasse

\section{$\begin{array}{llllllll}\text { A } & \text { B } & S & \mathbf{T} & \mathbf{R} & \mathbf{A} & \mathbf{C} & \mathbf{T}\end{array}$}

\section{Purpose}

Taxanes (paclitaxel or docetaxel) have been sequenced or combined with anthracyclines (doxorubicin or epirubicin) for the first-line treatment of advanced breast cancer. This meta-analysis uses data from all relevant trials to detect any advantages of taxanes in terms of tumor response, progression-free survival (PFS), and survival.

\section{Patients and Methods}

Individual patient data were collected on eight randomized combination trials comparing anthracyclines + taxanes (+ cyclophosphamide in one trial) with anthracyclines + cyclophosphamide (+ fluorouracil in four trials), and on three single-agent trials comparing taxanes with anthracyclines. Combination trials included 3,034 patients; single-agent trials included 919 patients.

\section{Results}

Median follow-up of alive patients was 43 months, median survival was 19.3 months, and median PFS was 7.1 months. In single-agent trials, response rates were similar in the taxanes (38\%) and in the anthracyclines (33\%) arms ( $P=.08)$. The hazard ratios for taxanes compared with anthracyclines were $1.19(95 \% \mathrm{Cl}, 1.04$ to $1.36 ; P=.011)$ for PFS and $1.01(95 \% \mathrm{Cl}, 0.88$ to $1.16 ; P=.90)$ for survival. In combination trials, response rates were $57 \%$ (10\% complete) in taxane-based combinations and $46 \%$ (6\% complete) in control arms $(P<.001)$. The hazard ratios for taxane-based combinations compared with control arms were $0.92(95 \% \mathrm{Cl}, 0.85$ to $0.99 ; P=.031)$ for $\mathrm{PFS}$ and $0.95(95 \% \mathrm{Cl}, 0.88$ to 1.03 ; $P=$.24) for survival.

\section{Conclusion}

Taxanes were significantly worse than single-agent anthracyclines in terms of PFS, but not in terms of response rates or survival. Taxane-based combinations were significantly better than anthracycline-based combinations in terms of response rates and PFS, but not in terms of survival.

\section{J Clin Oncol 26:000-000. (C) 2008 by American Society of Clinical Oncology}

\section{INTRODUCTION}

Taxanes constitute a drug class with important activity in metastatic breast cancer. Phase II trials showed that taxanes (paclitaxel and docetaxel) have similar efficacy as anthracyclines (doxorubicin and epirubicin) without cross-resistance, thus expanding the therapeutic strategies available in this disease.

Several studies explored the value of combining anthracyclines with taxanes, given that they have different mechanisms of action and are among the most active drugs against metastatic breast cancer. Randomized studies compared the efficacy of combinations of a taxane and an anthracycline versus a standard anthracycline-based regimen (anthracycline with cyclophosphamide with or without flu- orouracil) as first-line chemotherapy for metastatic breast cancer. ${ }^{1-8}$ Other studies investigated the efficacy of a single-agent taxane compared with a singleagent anthracycline..$^{9-11}$ The results of some of these trials were interesting but inconsistent when all trials were considered. In addition, the trials were inconclusive regarding a possible difference in survival among the treatment arms. It seemed important, therefore, to assess the benefits of taxanes quantitatively through an exhaustive meta-analysis of all the relevant trials. ${ }^{1-11}$

\section{PATIENTS AND METHODS}

\section{Trials}

Trials were eligible if they were randomized, closed to patient accrual before 2002, and compared either 
Piccart-Gebhart et al

anthracycline-taxane combination regimens versus anthracycline-based regimens, or single-agent anthracycline versus single-agent taxane regimens for the first-line treatment of metastatic breast cancer.

A MEDLINE and CANCERLIT search was performed to identify all eligible trials. Proceedings books from major oncologic and breast cancer meetings were examined for published results. To ensure that all relevant studies were included, researchers with area expertise were queried for the existence of unpublished trials. Eleven trials with 3,953 patients were found (Table 1). ${ }^{1-11}$

\section{Data}

The following data items were collected for all individual patients included in all trials: center, randomization date, date of last observation (or date of death, if the patient died), survival status, cause of death, tumor response (according to the WHO criteria ${ }^{12}$ ), date of tumor response, date of progression, progression status, number of organs involved at entry, visceral disease at entry (defined as predominantly visceral, if available, otherwise lung and/or liver), and estrogen receptor status at entry (defined as positive or negative according to each center's policy).

\section{Statistical Methods}

Classical methods for the meta-analysis of trials in metastatic disease were used. ${ }^{13}$ Tumor response was analyzed through a stratified MantelHaenszel test, with study as stratification factor. Time-related end points (survival and time to progression) were analyzed through a stratified log-rank test, with study as stratification factor. Forest plots were used to display odds ratios (of nonresponse) and hazard ratios (for progression-free survival and survival) within individual trials and overall. The hazard ratios compared the hazard or risk of an event (death for survival, death or progression for progression-free survival) in taxane-based regimens to the hazard or risk in anthracycline-based regimens. The odds ratios compared the odds of nonresponse in taxane-based regimens to the odds of nonresponse in anthracyclinebased regimens. Subset analyses were performed for the presence of visceral disease and for estrogen receptor status at entry. An interaction test was used to assess the statistical significance of any observed differences between the treatment effects in these subsets. All patients were included in the analyses as randomly assigned (intention to treat). All $P$ values were two sided. All CIs had a two-sided probability coverage of $95 \%$.

\section{RESULTS}

\section{Patient Characteristics}

Table 2 lists the characteristics of the 3,953 randomly assigned T2 patients separately for combination trials and for single-arm trials. There were no major differences in patient characteristics between treatment arms. Table 2 also lists summary statistics on the clinical outcomes of interest: response, median survival, and median progression-free survival.

\section{Survival}

Figure 1 shows the survival hazard ratios in individual trials and F1 overall. There was no indication of a benefit from taxanes, with an overall hazard ratio equal to 0.97 ( $95 \% \mathrm{CI}, 0.90$ to $1.04 ; P=.34$ ), corresponding to a $3 \%$ reduction of the hazard for taxane-based regimens. Some heterogeneity (variability of trial-specific hazard ratios) was apparent in the results of combination trials (test for interaction, $P=.043)$.

\section{Progression-Free Survival}

Figure 2 shows the progression-free survival hazard ratios in F2 individual trials and overall. There was some indication of a benefit of taxane combinations over nontaxane combinations, with an overall hazard ratio equal to 0.92 ( $95 \% \mathrm{CI}, 0.85$ to $0.99 ; P=.031)$, corresponding to an $8 \%$ reduction of the hazard of death or progression for taxane combinations, and of anthracyclines alone over taxanes alone, with an overall hazard ratio equal to 1.19 (95\% CI, 1.04 to 1.36; $P=.011)$, corresponding to a $19 \%$ increase of the hazard of death or progression for single-agent taxane regimens. Some heterogeneity was

\begin{tabular}{|c|c|c|c|}
\hline Trial & Dose, Control Arm (mg/m²) & Dose, Taxane Arm (mg/m²) & No. of Patients \\
\hline \multicolumn{3}{|l|}{ Combination trials } & 3,034 \\
\hline \multicolumn{3}{|l|}{ Paclitaxel } & 1,763 \\
\hline UKCCCR AB01 ${ }^{1}$ & Epi $75+$ Cyc 600 & Epi $75+$ Pac 200 & 705 \\
\hline $\mathrm{AGO}^{2}$ & Epi $60+$ Cyc 600 & Epi $60+$ Pac 175 & 516 \\
\hline EORTC $10961^{3}$ & Dox $60+$ Cyc 600 & Dox $60+$ Pac 175 & 275 \\
\hline CCEI Paclitaxel BCSG ${ }^{4}$ & Flu $500+$ Dox $50+$ Cyc 500 & Dox $50+$ Pac 220 & 267 \\
\hline \multicolumn{3}{|l|}{ Docetaxel } & 1,271 \\
\hline Tax 307 Study Group 5 & Flu $500+$ Dox $50+$ Cyc 500 & Doc $75+$ Dox $50+$ Cyc 500 & 484 \\
\hline Tax 306 Study Group 6 & Dox $60+$ Cyc 600 & Dox 50 + Doc 75 & 429 \\
\hline CCC Netherlands ${ }^{7}$ & Flu $500+$ Dox $50+$ Cyc 500 & Dox $50+$ Doc 75 & 216 \\
\hline French trial ${ }^{8}$ & Flu $500+$ Epi $75+$ Cyc 500 & Epi 75 + Doc 75 & 142 \\
\hline \multicolumn{3}{|l|}{ Single-agent trials } & 919 \\
\hline \multicolumn{3}{|l|}{ Paclitaxel } & 821 \\
\hline ECOG E11939 & Dox 60 & Pac 175 & 490 \\
\hline EORTC $10923^{10}$ & Dox 75 & Pac 200 & 331 \\
\hline \multicolumn{3}{|l|}{ Docetaxel } & 98 \\
\hline \multicolumn{3}{|l|}{$\begin{array}{l}\text { Tax } 303 \text { Study } \\
\text { Group }\end{array}$} & 98 \\
\hline \multicolumn{3}{|l|}{ All trials } & 3,953 \\
\hline \multicolumn{4}{|c|}{$\begin{array}{l}\text { Abbreviations: dox, doxorubicin; cyc, cyclophosphamide; epi, epirubicin; flu, fluorouracil; pac, paclitaxel; doc, docetaxel; AGO, Arbeitsgemeinschaft Gynaekolo- } \\
\text { gische Onkologie; UKCCCR, United Kingdom Committee for Cancer Clinical Research; AB, Advanced Breast; EORTC, European Organisation for Research and } \\
\text { Treatment of Cancer; CCEI Paclitaxel BCSG, Central Europe and Israel Paclitaxel Breast Cancer Study Group; CCC, Comprehensive Cancer Centre; ECOG, Eastern } \\
\text { Cooperative Oncology Group. }\end{array}$} \\
\hline
\end{tabular}


Taxanes in Metastatic Breast Cancer

\begin{tabular}{|c|c|c|c|c|c|c|c|c|}
\hline \multirow[b]{3}{*}{ Characteristic } & \multicolumn{4}{|c|}{ Combination Trials } & \multicolumn{4}{|c|}{ Single Agent Trials } \\
\hline & \multicolumn{2}{|c|}{ Control Arm } & \multicolumn{2}{|c|}{ Taxane Arm } & \multicolumn{2}{|c|}{ Control Arm } & \multicolumn{2}{|c|}{ Taxane Arm } \\
\hline & $\begin{array}{c}\text { No. of } \\
\text { Patients }\end{array}$ & $\%$ & $\begin{array}{c}\text { No. of } \\
\text { Patients }\end{array}$ & $\%$ & $\begin{array}{c}\text { No. of } \\
\text { Patients }\end{array}$ & $\%$ & $\begin{array}{l}\text { No. of } \\
\text { Patients }\end{array}$ & $\%$ \\
\hline No. of patients & 1,512 & & 1,522 & & 455 & & 464 & \\
\hline Accrual period & \multicolumn{2}{|c|}{ 1981-1990 } & \multicolumn{2}{|c|}{$1981-1990$} & \multicolumn{2}{|c|}{$1981-1990$} & \multicolumn{2}{|c|}{$1981-1990$} \\
\hline \multicolumn{9}{|l|}{ Follow-up, months } \\
\hline Median & \multicolumn{2}{|l|}{39.8} & \multicolumn{2}{|l|}{38.6} & \multicolumn{2}{|l|}{60.1} & \multicolumn{2}{|l|}{59.0} \\
\hline Maximum & \multicolumn{2}{|l|}{76.2} & \multicolumn{2}{|l|}{80.2} & \multicolumn{2}{|l|}{100.5} & \multicolumn{2}{|l|}{91.3} \\
\hline \multicolumn{9}{|l|}{ Visceral disease } \\
\hline Yes & 876 & 70 & 875 & 69 & 314 & 69 & 345 & 74 \\
\hline No & 382 & 30 & 384 & 31 & 141 & 31 & 119 & 26 \\
\hline \multicolumn{9}{|l|}{ Estrogen receptor status } \\
\hline Positive & 465 & 60 & 453 & 58 & 159 & 53 & 176 & 55 \\
\hline Negative & 304 & 40 & 328 & 42 & 143 & 47 & 143 & 45 \\
\hline \multicolumn{9}{|l|}{ Tumor response } \\
\hline Complete & 94 & 6 & 149 & 10 & 25 & 6 & 18 & 4 \\
\hline Partial & 599 & 40 & 725 & 48 & 148 & 33 & 133 & 29 \\
\hline Stable disease & 510 & 34 & 396 & 26 & 169 & 37 & 184 & 40 \\
\hline Progressive disease & 207 & 13 & 117 & 7 & 70 & 15 & 95 & 20 \\
\hline Not assessable & 102 & 7 & 135 & 9 & 40 & 9 & 33 & 7 \\
\hline \multicolumn{9}{|l|}{ Progression-free survival } \\
\hline Median & \multicolumn{2}{|c|}{6.9} & \multicolumn{2}{|c|}{7.7} & \multicolumn{2}{|c|}{7.2} & \multicolumn{2}{|c|}{5.1} \\
\hline $95 \% \mathrm{Cl}$ & \multicolumn{2}{|c|}{6.5 to 7.2} & \multicolumn{2}{|c|}{7.2 to 8.0} & & & & \\
\hline Overall survival & & & & & & & & \\
\hline Median & & & & & & & & \\
\hline $95 \% \mathrm{Cl}$ & & & & & & & & \\
\hline Time from progression & & & & & & & & \\
\hline Median & & & & & & & & \\
\hline $95 \% \mathrm{Cl}$ & & & & & & & & \\
\hline
\end{tabular}

seen in combination trials (test for interaction, $P=.09$ ), and considerable heterogeneity was seen in single-arm trials (test for interaction, $P=.001$ ), with all of the treatment effect arising from the European Organisation for Research and Treatment of Cancer (EORTC) 10923 trial (exclusion of this trial resulted in a nonsignificant hazard ratio close to 1 , which is compatible with the estimates obtained for the remaining combination trials).

\section{Tumor Response}

Figure 3 shows the nonresponse odds ratios in individual trials and overall. There was strong benefit of taxane combinations over nontaxane combinations, with a response rate of $57 \%$ (10\% complete responses) versus $46 \%$ (6\% complete responses; stratified nonresponse odds ratio $=0.63 ; 95 \% \mathrm{CI}, 0.54$ to $0.72 ; P<.001$, corresponding to a $27 \%$ reduction of the odds of nonresponse for taxane combinations). There was a moderate benefit of anthracyclines alone over taxanes alone, with a response rate of $38 \%$ (6\% complete responses) versus 33\% (4\% complete responses; stratified nonresponse odds ratio $=1.29 ; 95 \% \mathrm{CI}, 0.99$ to $1.70 ; P=.063$, corresponding to a $29 \%$ increase of the odds of nonresponse for single-agent taxane regimens). Some heterogeneity was seen in single-arm trials (test for interaction, $P=.07$ ), with all of the treatment effect arising from the EORTC 10923 trial (exclusion of this trial resulted in a nonsignificant hazard ratio close to 1 , which is compatible with the estimates obtained for the remaining combination trials).
Appendix Figure A1 (online only) shows the nonresponse odds ratios in combination trials, separately for patients with and without visceral disease at entry on trial. There was no indication that the benefit of taxanes was more pronounced among patients with visceral disease than among those without visceral disease (test for interaction, $P=.12$ ). The same observation was made in single-arm trials (test for interaction, $P=.69$ ).

Appendix Figure A2 (online only) shows the nonresponse odds ratios in combination trials, separately for patients who were estrogen receptor-positive and-negative at entry on trial. There was no indication that the benefit of taxanes was more pronounced among patients who were estrogen receptor-negative (test for interaction, $P=.34$ ). The same observation was made in singlearm trials (test for interaction, $P=.64$ ).

\section{Potential Causes of Heterogeneity Between the Randomized Trials}

The trials clearly differed as far as anthracycline type and dose, taxane type and dose or schedule (Table 1). Table 3 compares the trials in terms of outcome of the control arm, cross-over rates to taxanes in the control arm, and key patient characteristics. Two trials were characterized by lower cross-over rates to taxanes ${ }^{4,6}$; interestingly, one of them showed a survival gain for the taxane-treated patients. ${ }^{4}$ Two trials showed a particularly poor outcome of the control arm, ${ }^{1,7}$ with a median survival of 14 to 16 months; again, one of these also showed a survival gain for the taxane-treated patients. ${ }^{7}$ Two trials 


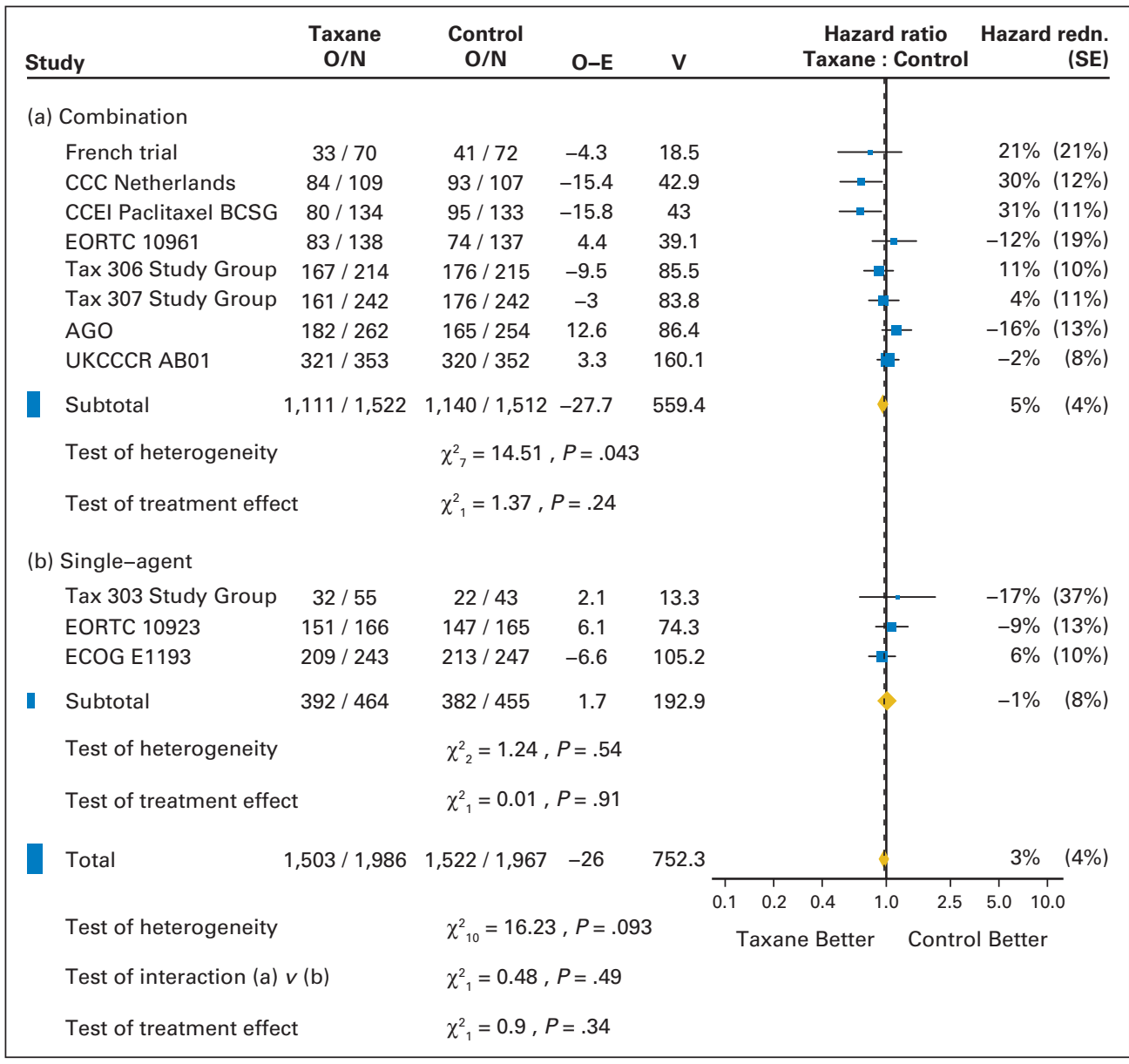

Fig 1. Overall survival hazard ratios. $O$ observed; $N$, total number of patients; $E$, expected, $\mathrm{V}$, variance; redn., reduction; CCC, Comprehensive Cancer Centre; CCEI, Central Europe and Israel; BCSG, Breast Cancer Study Group; EORTC, European Organisation for Research and Treatment of Cancer; AGO, Arbeitsgemeinschaft Gynaekologische Onkologie; UKCCCR, United Kingdom Committee for Cancer Clinical Research. enrolled a large proportion of patients $(>70 \%)$ exposed to prior endocrine therapy.

Appendix Figures A3 and A4 (online only) present, respectively, survival and progression-free survival curves per trial and overall. The curves show a limited-if any-benefit of taxanes. If one accepts this lack of benefit, the observed heterogeneity may well be just random variation.

\section{DISCUSSION}

The taxanes, paclitaxel and docetaxel, generated a great deal of enthusiasm in the 1990s, when they demonstrated a lack of cross-resistance with the anthracyclines in advanced breast cancer. Considerable interest arose to compare them head to head with anthracyclines, but also to associate them with anthracyclines in front-line regimens for this disease, the median survival of which had not changed much in the last two decades. In 2002, results of 12 such randomized trials were available, with two trials showing a survival gain with the incorporation of a taxane in front-line therapy. ${ }^{4,7}$ In addition, results in terms of objective response rate and progression-free survival were inconsistent, leaving the oncology community divided as to whether or not these new drugs, associated with greater toxicity and cost, should be used up AQ: D front in the treatment of metastatic breast cancer. This debate moti- vated the present meta-analysis, which turned out to be more difficult than anticipated: indeed, two pharmaceutical companies were involved, each with a taxane on the market, and both were reluctant to share the databases of the clinical trials they had sponsored (however, eventually, they agreed to provide the data).

Our results show that doxorubicin alone is better than a taxane alone for the first-line treatment of patients with advanced breast cancer. However, this result is entirely driven by a single trial — a trial conducted by the EORTC — in which paclitaxel given at $175 \mathrm{mg} / \mathrm{m}^{2}$ as a 3-hour infusion was compared with doxorubicin at 75 $\mathrm{mg} / \mathrm{m}^{2}$. This result, therefore, is of little relevance for the first-line regimens used today.

The choice of an optimal first-line combination using anthracyclines and taxanes has been the focus of most trials included in the present meta-analysis. If our results confirm the benefit of taxanes in terms of response rate $(57 \% v 46 \%$; stratified nonresponse odds ratio $=0.63 ; P<.001$ ) and of progression-free survival (median PFS $=6.9 \vee 7.7$ months; hazard ratio $=0.92 ; P=.031)$, they fail to identify a significant benefit in terms of survival (median survival $=19.2 v 19.8$ months; hazard ratio $=0.95 ; P=.24$; with a median follow-up of more than 40 months). They also suggest that in this set of trials, neither response nor PFS was a good surrogate for survival, an issue that is taken up in greater detail in a companion paper (Burzykowski et $\mathrm{al}^{14}$ ). 


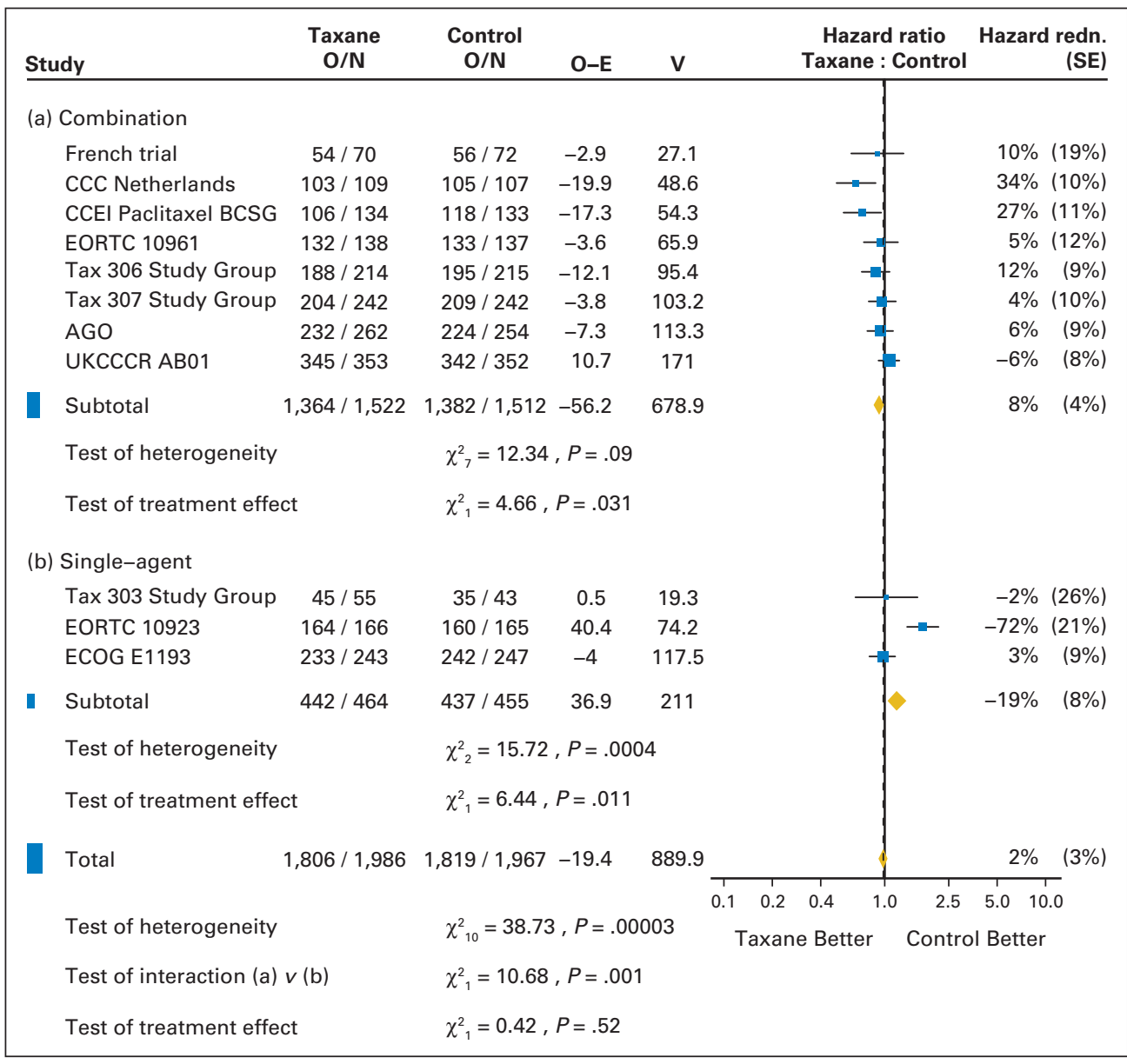

Fig 2. Progression-free survival hazard ratios. $O$, observed; $N$, total number of patients; $E_{\text {, }}$ expected, V, variance; redn., reduction; CCC, Comprehensive Cancer Centre; CCEI, Central Europe and Israel; BCSG, Breast Cancer Study Group: EORTC, European Organisation for Research and Treatment of Cancer; AGO, Arbeitsgemeinschaft Gynaekologische Onkologie; UKCCCR, United Kingdom Committee for Cancer Clinical Research.
Our results seem to be at variance with those obtained by Ghershi et $\mathrm{al}^{15}$ in a meta-analysis based on data extracted from published trial reports. However, Gershi et al considered trials with any taxanecontaining treatments compared with any nontaxane treatments, whether given in first-line or not. When they restricted their analyses to first-line treatments, the survival benefit was no longer statistically significant. In addition, their trials included a number of treatments that would be regarded as inadequate today, whereas we only considered treatments that included at least an anthracycline or a taxane.

Our group had postulated that the benefit of taxanes, if any, would be more pronounced among patients with worse prognosis at entry on trial (patients with visceral disease and without estrogen receptors). Neither of these hypotheses was supported by the data, whether in terms of response (the most sensitive end point to investigate such a treatment by subset interaction), progression-free survival, or survival.

Substantial heterogeneity was seen between the results of the various trials even when combination trials were considered separately from single-agent trials. Such heterogeneity can in part be explained by differences in patient populations and access to taxanes for the control groups (as listed in Table 3), but it does not invalidate our findings. The modesty of the benefit of taxanes on the most clinically relevant end points is somewhat unexpected and emphasizes the usefulness of assessing the results of individual clinical trials (some of which inevitably look more promising just by chance) in the context of all other similar trials. These modest benefits also emphasize the need for more translational research in breast cancer, with clinical trials increasingly run in better-defined molecular subpopulations.

We believe the present meta-analysis provides four useful messages to the clinical and scientific community: (1) in metastatic breast cancer, taxanes do not improve survival when compared with anthracyclines, either as single agents, or in anthracycline combinations; (2) taxanes in combination with anthracyclines modestly improve response rates and PFS; (3) more attention needs to be paid to cross-over from an older agent to a newer drug when designing clinical trials and reporting their results; and (4) clinical trial databases should be coowned by academia and industry, to facilitate analyses beyond the primary report or publication.

\section{AUTHORS' DISCLOSURES OF POTENTIAL CONFLICTS OF INTEREST}

Although all authors completed the disclosure declaration, the following authors or their immediate family members indicated a financial interest. No conflict exists for drugs or devices used in a study if they are not being evaluated as part of the investigation. For a detailed description of the disclosure categories, or for more information about ASCO's conflict of interest policy, please refer to the Author Disclosure Declaration and the Disclosures of Potential Conflicts of Interest section in Information for Contributors.

Employment: N/A Leadership: N/A Consultant: Martine J.

Piccart-Gebhart, Sanofi-aventis, Bristol-Myers Squibb; Hans-Joachim Luck, Sanofi-aventis, Bristol-Myers Squibb, AstraZeneca, Novartis, 


\section{Piccart-Gebhart et al}

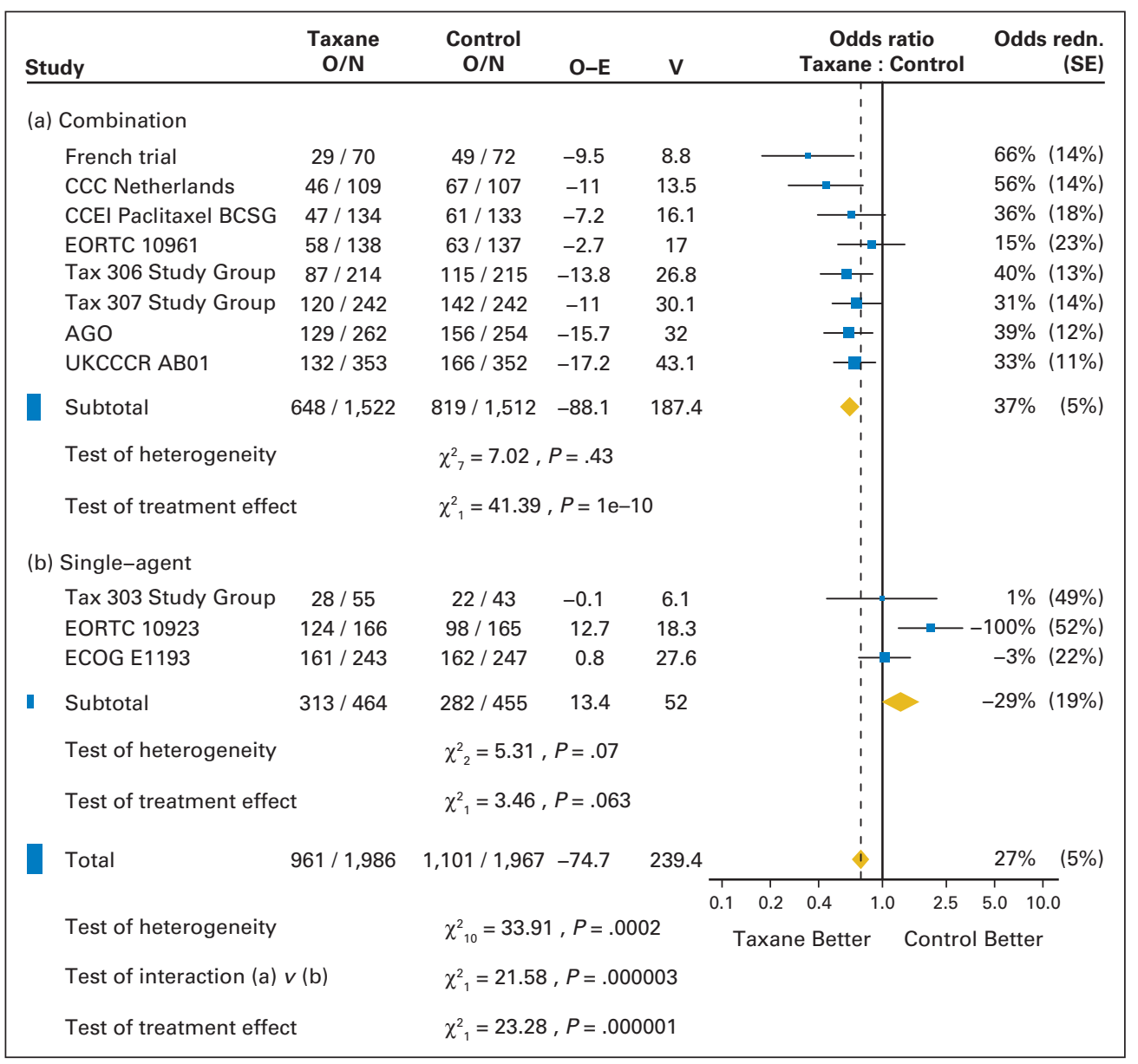

Fig 3. Failure to respond odds ratios. $\mathrm{O}$, observed; $\mathrm{N}$, total number of patients; $\mathrm{E}$, expected, $V$, variance; redn., reduction; CCC, Comprehensive Cancer Centre; CCEl, Central Europe and Israel; BCSG, Breast Cancer Study Group; EORTC, European Organisation for Research and Treatment of Cancer; AGO, Arbeitsgemeinschaft Gynaekologische Onkologie; UKCCCR, United Kingdom Committee for Cancer Clinical Research.

Roche; John R. Mackey, Sanofi-aventis, Amgen Stock: N/A Honoraria: Martine J. Piccart-Gebhart, Sanofi-aventis, Bristol-Myers Squibb; Hans-Joachim Luck, Sanofi-aventis, Bristol-Myers Squibb, AstraZeneca, Novartis, Roche; John R. Mackey, Sanofi-aventis, Amgen Research Funds: George Sledge, Sanofi-aventis Testimony: N/A Other: Marijke Bontenbal, Sanofi-aventis

\section{AUTHOR CONTRIBUTIONS}

Conception and design: Martine J. Piccart-Gebhart, Marc Buyse, Laura Biganzoli

Administrative support: Tomasz Burzykowski, Marc Buyse

\begin{tabular}{|c|c|c|c|c|c|c|c|c|c|c|c|}
\hline \multirow[b]{3}{*}{$\begin{array}{c}\text { Potential Causes of } \\
\text { Heterogeneity }\end{array}$} & \multicolumn{8}{|c|}{ Combination Trials } & \multicolumn{3}{|c|}{ Single-Agent Trials } \\
\hline & \multicolumn{4}{|c|}{ Paclitaxel Based } & \multicolumn{4}{|c|}{ Docetaxel Based } & \multicolumn{2}{|c|}{ Paclitaxel } & Docetaxel \\
\hline & $\begin{array}{l}\mathrm{Epi}+\mathrm{Cyc} v \\
\mathrm{Epi}+\mathrm{Pac}^{1}\end{array}$ & $\begin{array}{l}\mathrm{Epi}+\mathrm{Cyc} v \\
\mathrm{Epi}+\mathrm{Pac}^{2}\end{array}$ & $\begin{array}{l}\mathrm{Dox}+\mathrm{Cyc} v \\
\mathrm{Dox}+\mathrm{Pac}^{3}\end{array}$ & $\begin{array}{c}\mathrm{Flu}+\mathrm{Dox}+ \\
\text { Cyc } \vee \text { Dox }+ \\
\mathrm{Pac}^{4}\end{array}$ & $\begin{array}{l}\text { Flu + Dox }+ \\
\text { Cyc } v \text { Dox }+ \\
\text { Doc }+ \text { Cyc }\end{array}$ & $\begin{array}{l}\text { Dox }+ \text { Cyc v } \\
\text { Dox }+ \text { Doc }^{6}\end{array}$ & $\begin{array}{c}\mathrm{Flu}+\mathrm{Dox}+ \\
\text { Cyc } v \text { Dox }+ \\
\text { Doc }^{7}\end{array}$ & $\begin{array}{c}\text { Flu }+ \text { Epi }+ \\
\text { Cyc } \vee \text { Epi }+ \\
\text { Doc }^{8}\end{array}$ & $\begin{array}{l}\text { Dox } v \\
\operatorname{Pac}^{9}\end{array}$ & $\begin{array}{l}\text { Dox } v \\
\operatorname{Pac}^{10}\end{array}$ & $\begin{array}{l}\operatorname{Dox} v \\
\operatorname{Doc}^{11}\end{array}$ \\
\hline $\begin{array}{c}\text { Cross-over to taxane in } \\
\text { control arm (\%) }\end{array}$ & $?$ & $?$ & $?$ & 24 & $?$ & 29 & $?$ & 57 & 52 & 47 & $?$ \\
\hline $\begin{array}{l}\text { Median survival of control } \\
\text { arm (months) }\end{array}$ & 13.9 & 22.1 & 23.7 & 18.3 & 22.0 & 21.7 & 16.2 & 28.0 & 18.9 & 18.1 & 21.7 \\
\hline $\begin{array}{c}\text { Patients with prior adjuvant } \\
\text { chemotherapy }(\%)\end{array}$ & 54 & 43 & 36 & 45 & 40 & 42 & 31 & 49 & 31 & 33 & $?$ \\
\hline $\begin{array}{l}\text { Patients with prior } \\
\text { endocrine therapy (\%) }\end{array}$ & 72 & $?$ & 57 & 35 & $?$ & $?$ & 54 & $?$ & $\geq 30$ & 75 & $?$ \\
\hline $\begin{array}{c}\text { Patients with visceral } \\
\text { disease (\%) }\end{array}$ & 65 & $?$ & 83 & 66 & 71 & 62 & 76 & 81 & 68 & 77 & 76 \\
\hline $\begin{array}{l}\text { Patients with with } \geq 3 \\
\text { metastatic sites (\%) }\end{array}$ & $?$ & $?$ & $?$ & 35 & 48 & 41 & 43 & 55 & 17 & $?$ & 42 \\
\hline
\end{tabular}




\section{Taxanes in Metastatic Breast Cancer}

Provision of study materials or patients: George Sledge, James Carmichael, Hans-Joachim Luck, John R. Mackey, Jean-Marc Nabholtz, Robert Paridaens, Laura Biganzoli, Jacek Jassem, Marijke Bontenbal, Jacques Bonneterre, Stephen Chan, Gul Atalay Basaran, Patrick Therasse Collection and assembly of data: Tomasz Burzykowski Data analysis and interpretation: Martine J. Piccart-Gebhart, Tomasz Burzykowski, Marc Buyse
Manuscript writing: Martine J. Piccart-Gebhart, Tomasz Burzykowski, Marc Buyse

Final approval of manuscript: Martine J. Piccart-Gebhart, Tomasz Burzykowski, Marc Buyse, George Sledge, James Carmichael, Hans-Joachim Luck, John R. Mackey, Jean-Marc Nabholtz, Robert Paridaens, Laura Biganzoli, Jacek Jassem, Marijke Bontenbal, Jacques Bonneterre, Stephen Chan, Gul Atalay Basaran, Patrick Therasse

\section{REFERENCES}

1. Carmichael J: UKCCCR trial of epirubicin and cyclophosphamide $(E C)$ vs. epirubicin and Taxol (ET) in the first line treatment of women with metastatic breast cancer (MBC). Proc Am Soc Clin Oncol 20: 22a, 2001 (abstr 84)

2. Luck HJ, Thomssen $C$, Untch M, et al: Multicentric phase III study in first line treatment of advanced breast cancer (ABC): Epirubicin/paclitaxel (ET) vs epirubicin/cyclophosphamide (EC)—A study of the AGO Breast Cancer Group. Proc Am Soc Clin Oncol 19:73, 2000 (abstr 280)

3. Biganzoli L, Cufer $T$, Bruning $P$, et al: Doxorubicin and paclitaxel versus doxorubicin and cyclophosphamide as first-line chemotherapy in metastatic breast cancer: The European Organization for Research and Treatment of Cancer 10961 multicenter phase III trial. J Clin Oncol 20:3114-3121, 2002

4. Jassem J, Pienkowski T, Pluzanska A, et al: Doxorubicin and paclitaxel versus fluorouracil, doxorubicin, and cyclophosphamide as first-line therapy for women with metastatic breast cancer: Final results of a randomized phase III multicenter trial. J Clin Oncol 19:1707-1715, 2001

5. Mackey JR, Paterson A, Dirix L, et al: Final results of the phase III randomised trial comparing docetaxel (T), doxorubicin (A) and cyclophospha- mide (C) to FAC as first line chemotherapy (CT) for patients (pts) with metastatic breast cancer (MBC). Proc Am Soc Clin Oncol 21:35a, 2002 (abstr 137)

6. Nabholtz JM, Falkson G, Campos D, et al: Docetaxel and doxorubicin compared with doxorubicin and cyclophosphamide as first-line chemotherapy for metastatic breast cancer: Results of a randomized, multicenter, phase III trial. J Clin Oncol 21:968-975, 2003

7. Bontenbal M, Creemers GJ, Braun HJ, et al: Phase II to III study comparing doxorubicin and docetaxel with fluorouracil, doxorubicin, and cyclophosphamide as first-line chemotherapy in patients with metastatic breast cancer: Results of a Dutch community setting trial for the Clinical Trial Group of the Comprehensive Cancer Centre. J Clin Oncol 23:7081-7088, 2005

8. Bonneterre J, Dieras V, Tubiana-Hulin M, et al: Phase II multicentre randomised study of deocetaxel plus epirubicinversus 5-fluorouracil plus epirubicin and cyclophosphamide in metastatic breast cancer. Br J Cancer 91:1466-1471, 2004

9. Sledge GW, Neuberg D, Bernardo $P$, et al: Phase III trial of doxorubicin, paclitaxel and the combination of doxorubicin and paclitaxel as frontline chemotherapy for metastatic breast cancer: An intergroup trial (E1193). J Clin Oncol 21:588-592, 2003
10. Paridaens $R$, Biganzoli $L$, Bruning $P$, et al: Paclitaxel versus doxorubicin as first-line singleagent chemotherapy for metastatic breast cancer: A European Organization for Research and Treatment of Cancer randomised study with cross-over. J Clin Oncol 18:724-733, 2000

11. Chan S, Friedrichs $K$, Noel D, et al: Prospective randomised trial of docetaxel versus doxorubicin in patients with metastatic breast cancer: The 303 Study Group. J Clin Oncol 17:2341-2354, 1999

12. World Health Organisation.WHO Handbook for Reporting Results of Cancer Treatment: WHO Offset Publication No. 48. Geneva, Switzerland, World Health Organization, 1979

13. Advanced Colorectal Cancer Meta-Analysis Project: Modulation of 5-fluorouracil by leucovorin in patients with advanced colorectal cancer-Evidence in terms of response rate. J Clin Oncol 10:896-903, 1992

14. Burzykowski T, Buyse M, Piccart-Gebhart MJ, et al: Evaluation of tumor response, disease control, progression-free survival, and time to progression as potential surrogate endpoints in metastatic breast cancer. J Clin Oncol doi:10.1200/JCO.2007.10.8407

15. Ghersi D, Wilcken N, Simes RJ: A systematic review of taxane-containing regimens for metastatic breast cancer. Br J Cancer 93:293-301, 2005

\section{Acknowledgment}

We thank the collaborative groups, Sanofi-Synthelabo, and Bristol-Myers Squibb for providing individual patient data. 
Piccart-Gebhart et al

\section{Appendix}

AQ: G

FA1-FA4

\begin{tabular}{|c|c|c|c|c|c|c|c|c|c|}
\hline \multicolumn{2}{|c|}{ Study } & \multirow[t]{2}{*}{$\begin{array}{c}\text { Taxane } \\
\text { O/N }\end{array}$} & \multirow[t]{2}{*}{$\begin{array}{c}\text { Control } \\
\mathrm{O} / \mathrm{N}\end{array}$} & \multirow[t]{2}{*}{ O-E } & \multirow[t]{2}{*}{$\mathbf{v}$} & \multicolumn{2}{|c|}{$\begin{array}{c}\text { Odds ratio } \\
\text { Taxane : Control }\end{array}$} & \multicolumn{2}{|c|}{$\begin{array}{r}\text { Odds redn. } \\
\text { (SE) }\end{array}$} \\
\hline \multicolumn{6}{|c|}{ (a) No visceral disease } & & & & \\
\hline & French trial & $5 / 10$ & $8 / 17$ & 0.2 & 1.6 & $\frac{1}{1}$ & & $=12 \%$ ( & (133\%) \\
\hline & CCC Netherlands & $14 / 30$ & $12 / 21$ & -1.3 & 3.1 & 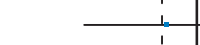 & & $34 \%$ & $(50 \%)$ \\
\hline & CCEI Paclitaxel BCSG & $12 / 48$ & $13 / 43$ & -1.2 & 4.6 & $\frac{1}{1}$ & & $23 \%$ & $(46 \%)$ \\
\hline & EORTC 10961 & $6 / 20$ & $10 / 26$ & -1 & 2.6 & $\frac{1}{1}$ & & $31 \%$ & $(59 \%)$ \\
\hline & Tax 306 Study Group & $32 / 84$ & $35 / 79$ & -2.5 & 9.9 & $+=$ & — & $22 \%$ & $(29 \%)$ \\
\hline & Tax 307 Study Group & $31 / 67$ & $45 / 72$ & -5.6 & 8.7 & $-\frac{1}{1}$ & & $48 \%$ & $(21 \%)$ \\
\hline & UKCCCR AB01 & $47 / 126$ & $48 / 124$ & -0.9 & 14.8 & 1 & - & $6 \%$ & $(28 \%)$ \\
\hline \multirow[t]{3}{*}{ ! } & Subtotal & 147 / 385 & $171 / 382$ & -12.3 & 45.3 & 1 & & $24 \%$ & $(12 \%)$ \\
\hline & \multicolumn{2}{|l|}{ Test of heterogeneity } & \multicolumn{3}{|c|}{$\chi_{6}^{2}=2.24, P=.90$} & i & & & \\
\hline & \multicolumn{2}{|l|}{ Test of treatment effect } & \multicolumn{3}{|c|}{$\chi_{1}^{2}=3.33, P=.068$} & 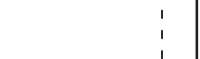 & & & \\
\hline \multicolumn{10}{|c|}{ (b) Visceral disease } \\
\hline & French trial & $24 / 60$ & $41 / 55$ & -9.9 & 7.1 & $-\vdots$ & & $75 \%$ & $(11 \%)$ \\
\hline & CCC Netherlands & $32 / 79$ & $55 / 86$ & -9.7 & 10.3 & $=1$ & & $61 \%$ & $(14 \%)$ \\
\hline & CCEI Paclitaxel BCSG & $35 / 86$ & $48 / 90$ & -5.6 & 11 & 7 & & $40 \%$ & $(21 \%)$ \\
\hline & EORTC 10961 & $52 / 118$ & $53 / 111$ & -2.1 & 14.3 & $一+$ & - & $14 \%$ & $(26 \%)$ \\
\hline & Tax 306 Study Group & $55 / 130$ & $80 / 136$ & -11 & 16.7 & $\rightarrow 1$ & & $48 \%$ & $(14 \%)$ \\
\hline & Tax 307 Study Group & $89 / 175$ & $97 / 170$ & -5.3 & 21.5 & $\perp-1$ & & $22 \%$ & $(19 \%)$ \\
\hline & UKCCCR AB01 & 85 / 227 & $118 / 228$ & -16.3 & 28.2 & $\rightarrow-$ & & $44 \%$ & $(12 \%)$ \\
\hline \multirow[t]{3}{*}{ 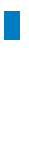 } & Subtotal & 372 / 875 & $492 / 876$ & -59.8 & 109.1 & $r_{1}$ & & $42 \%$ & $(6 \%)$ \\
\hline & \multicolumn{2}{|l|}{ Test of heterogeneity } & \multicolumn{3}{|c|}{$\chi_{6}^{2}=11.09, P=.086$} & & & & \\
\hline & \multicolumn{2}{|l|}{ Test of treatment effect } & \multicolumn{3}{|c|}{$\chi^{2}{ }_{1}=32.82, P=1 \mathrm{e}-08$} & $\vdots$ & & & \\
\hline \multicolumn{2}{|r|}{ Total } & $519 / 1,260$ & $663 / 1,258$ & -72.1 & 154.4 & $\phi$ & & $37 \%$ & $(5 \%)$ \\
\hline \multicolumn{3}{|c|}{ Test of heterogeneity } & \multicolumn{3}{|c|}{$\chi_{13}^{2}=15.79, P=.26$} & $\begin{array}{cccc}0.1 & 0.2 & 0.4 & 1 . \\
& & \\
T & \end{array}$ & $\begin{array}{l}0 \quad 2.5 \\
\text { Control }\end{array}$ & $\begin{array}{l}5.010 .0 \\
\text { Better }\end{array}$ & \\
\hline \multicolumn{3}{|c|}{ Test of interaction (a) $v(b)$} & \multicolumn{3}{|c|}{$\chi_{1}^{2}=2.47, P=.12$} & & & & \\
\hline \multicolumn{3}{|c|}{ Test of treatment effect } & \multicolumn{3}{|c|}{$\chi^{2}{ }_{1}=33.69, P=6 \mathrm{e}-09$} & & & & \\
\hline
\end{tabular}

Fig A1. Failure to respond odds ratios by visceral disease in combination trials. O, observed; N, total number of patients; E, expected, $V$, variance; redn., reduction; CCC, Comprehensive Cancer Centre; CCEI, Central Europe and Israel; BCSG, Breast Cancer Study Group; EORTC, European Organisation for Research and Treatment of Cancer; AGO, Arbeitsgemeinschaft Gynaekologische Onkologie; UKCCCR, United Kingdom Committee for Cancer Clinical Research. 
Taxanes in Metastatic Breast Cancer

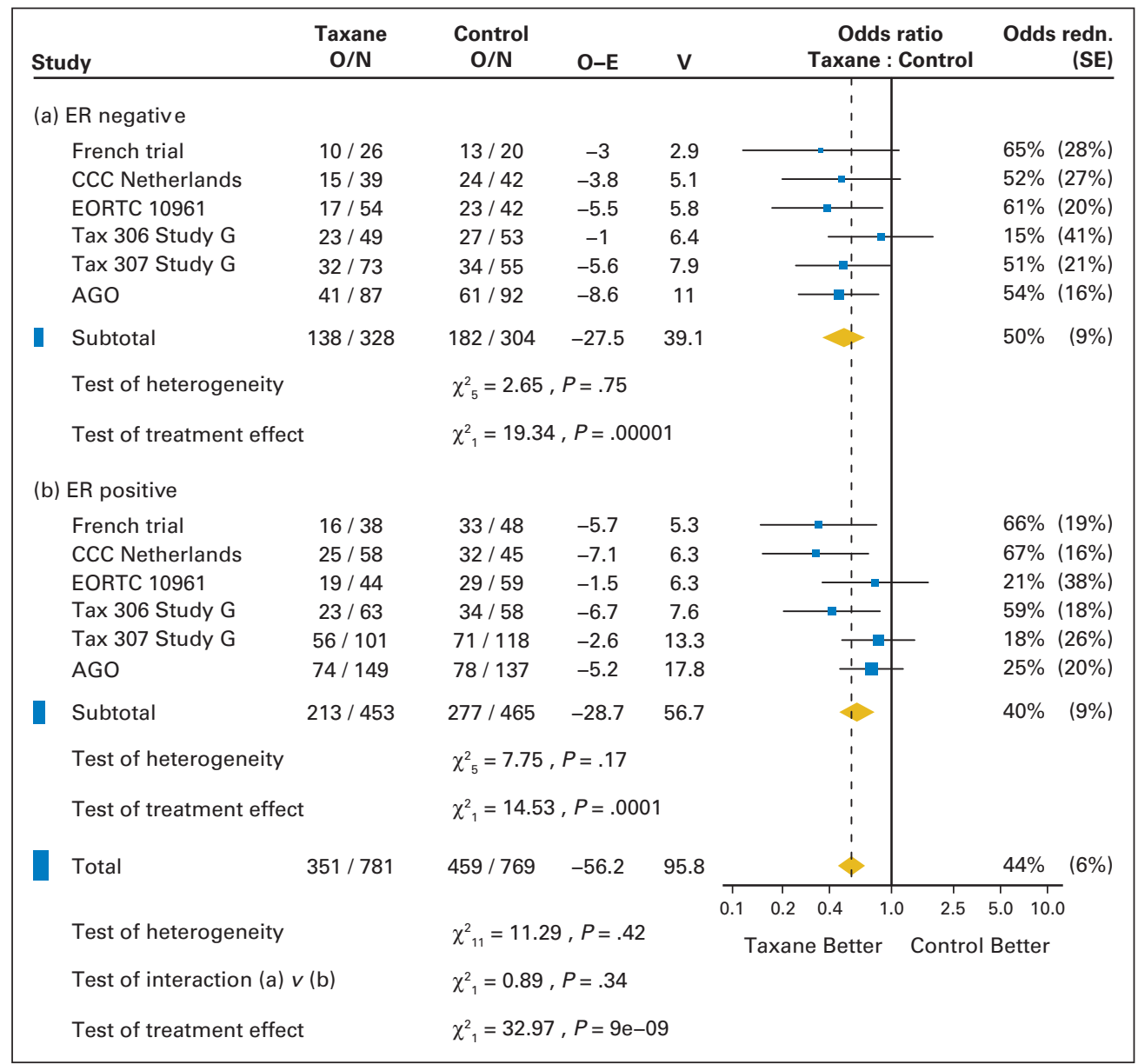

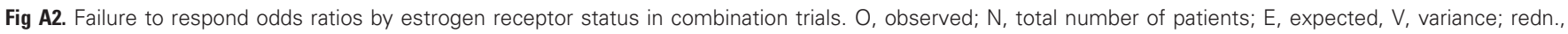

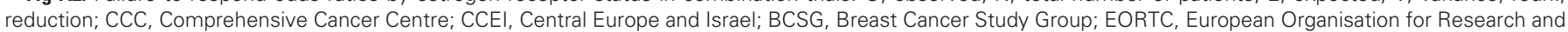
Treatment of Cancer; AGO, Arbeitsgemeinschaft Gynaekologische Onkologie; UKCCCR, United Kingdom Committee for Cancer Clinical Research. 
Piccart-Gebhart et al

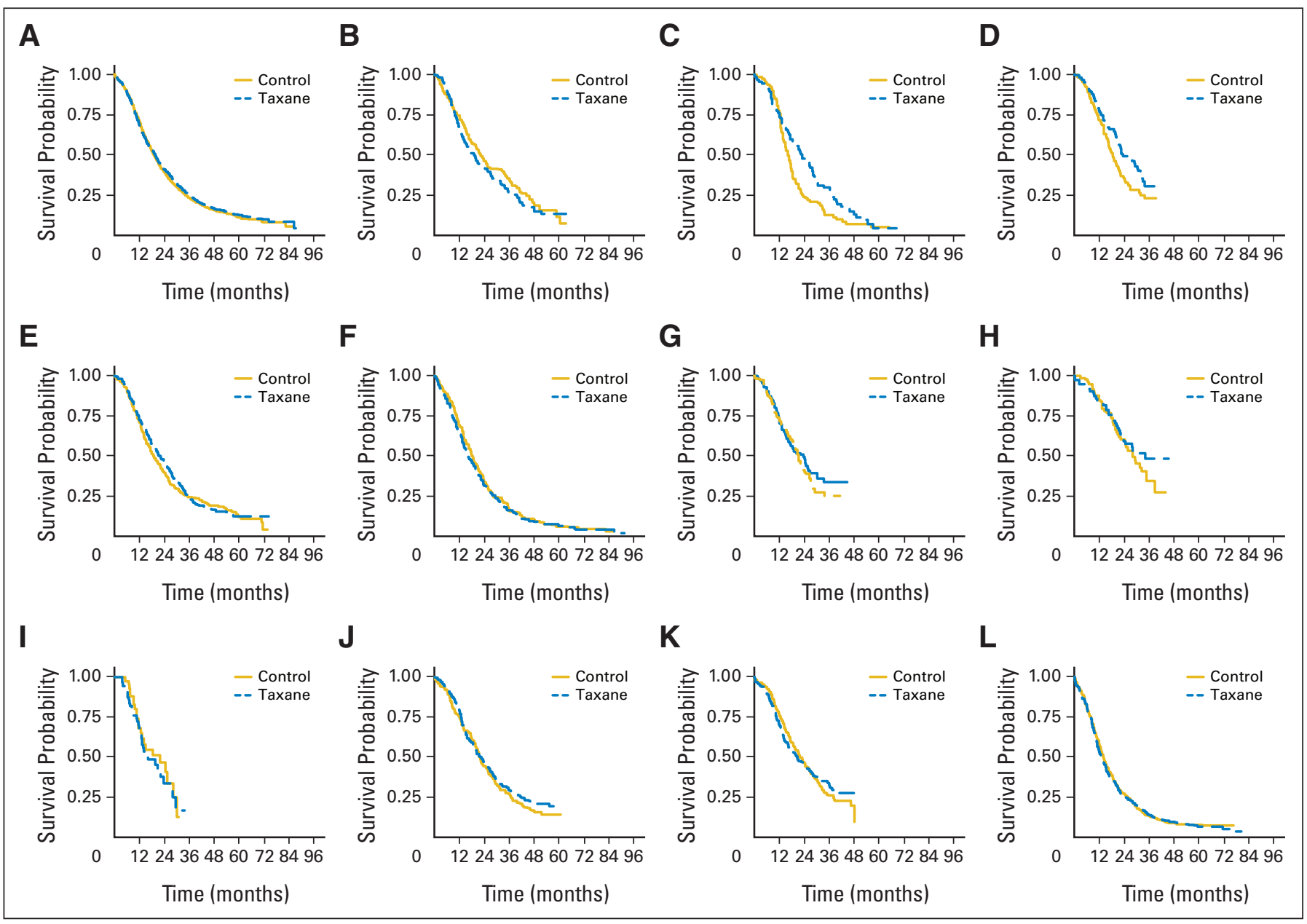

AQ: $\mathrm{K}$

Fig A3. Survival curves by treatment arm (overall and per trial). 
Taxanes in Metastatic Breast Cancer

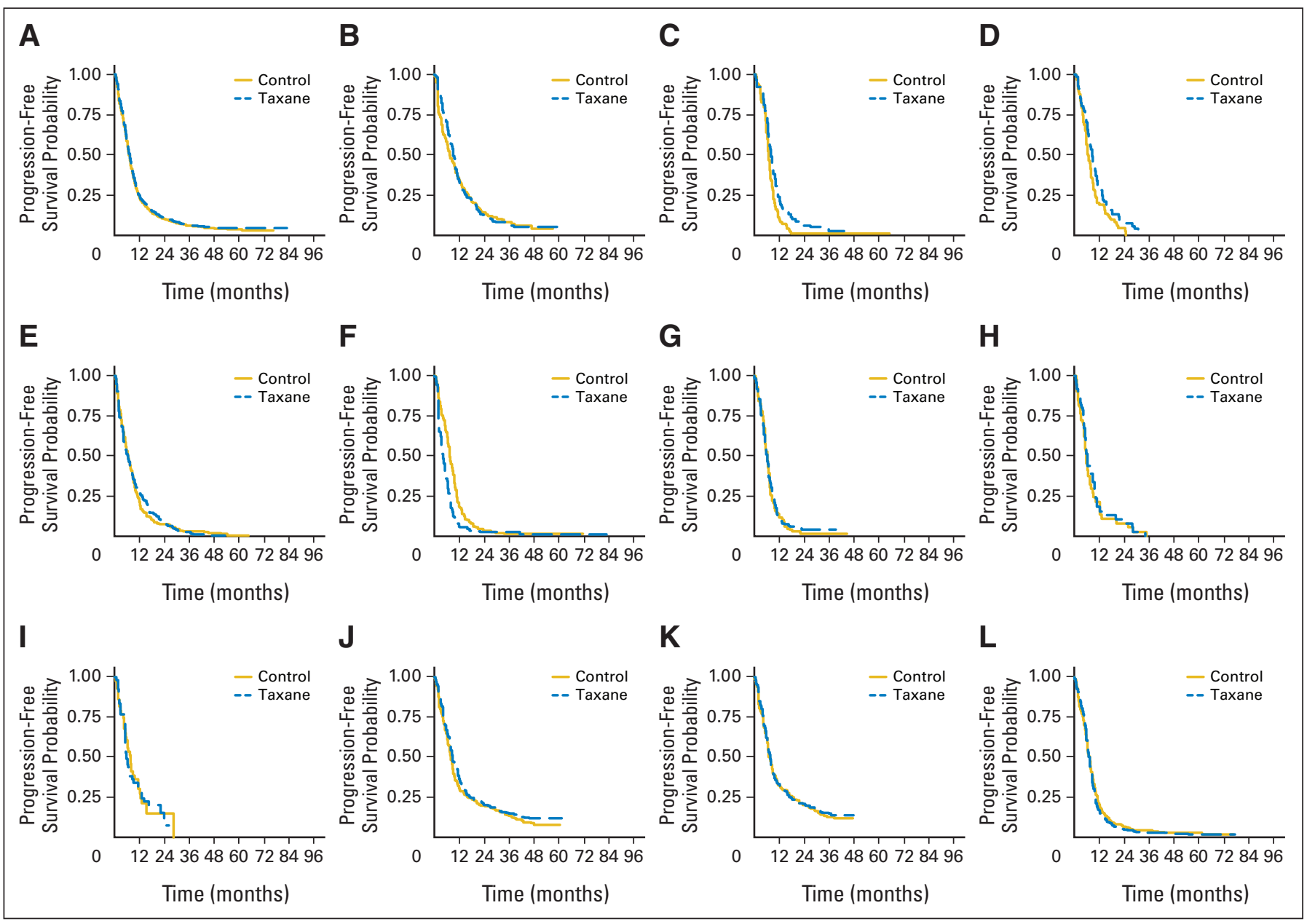

Fig A4. Progression-free survival curves by treatment arm (overall and per trial). 